\title{
Research on Service Innovation of University Library under MOOCs
}

\author{
Xiumei Luan \\ School of Mechanical \& Automotive Engineering \\ Qilu University of Technology \\ Jinan, 250353, China \\ Luan_xm@163.com
}

\begin{abstract}
Due to the appearance of MOOCs, great changes have taken place in the mode of teaching, and university library also meets the opportunities and the challenges as an auxiliary teaching institution. This paper describes the impact of MOOCs' development on university libraries, puts forward that university library should actively offer the course of information literacy and strengthen the construction of reference resources, the guidances of copyrights and the services of learning's space to build MOOCS and provide innovative services for the teachers and students under MOOCs.
\end{abstract}

Keywords- MOOCs; University library; Information literacy; Subject librarian; Copyright; Learning space

\section{INTRODUCTION}

MOOCs ( Massive Open Online Courses ) caused widespread concern of the education circle and the public since 2012 and then entered the stage of rapid development. This new teaching mode has brought huge impact to the higher education and new challenges and opportunities to the university library. Now the service mode of university library has become a hot topic of people debate in the context of MOOCs. University Library as an auxiliary teaching institution in colleges and universities, needs to understand the MOOCs well and prepare it. It must consider how to carry on the service innovation, and provides powerful support for MOOCs. Play an active role in the reform of the new teaching mode.

Foreign scholars have done some research on the model of MOOCs service of libraries. The literature [1] discusses the service of research libraries in the information resources and academic papers in the context of MOOCs and put forward the value and significance of MOOCs' teaching practice which the research libraries take part in. The literature [2] describes the form and content of University Library Service in the context of MOOCs. Foreign libraries' MOOCs service mode have good effect on the University Libraries of our country and the domestic scholars also actively explore the university library MOOCs service mode to suitable for the situation of our country. The literature [3, 4] discusses the university library's strategy to cope with the challenge of MOOCs and studies the library service pattern innovation. The literature [5] discusses how to construct electronic learning environment in University Library under the trend of MOOCs. The library actively participates in the course construction and the creation of "information literacy". These studies will be very important for the development of library service in our country.

This paper describes the impact of MOOCs' development on university libraries, puts forward that university library should actively offer the course of information literacy and strengthen the construction of reference resources, the guidances of copyrights and the services of learning's space to build MOOCS and provide innovative services for the teachers and students under MOOCs.

\section{THE IMPACT OF MOOCS ON UNIVERSITY LIBRARY}

University library, as the information center, should play an important role in the rapid development of MOOCs by virtue of their superior information resources and service advantages. But the MOOCs is still in the early stages of development and the university library has just touched of MOOCs environment. There are many problems to be solved in the future that how library services MOOCs teaching.

\section{A. Changes of library service needs of MOOCs teaching team}

In recent years, with the development of the Internet, more and more information is generated, and the importance of the University Library's service as an information resource center becomes more and more weak. Along with the MOOCs' rapid development, some librarians lack of confidence in the construction of curriculum which the library takes part in . The literature [9] thinks, library which is on the background of MOOCs is no hope, because it is not on the demand. Although this view is too pessimistic, there is some truth. MOOCs teaching platforms such as Coursera, Udacity and edX whose curriculums are with a series of short videos by the teacher around the theme (usually no more than 8-12 minutes, lasting four to six weeks).The students finish the exercises work and interactive discussion by watching the video. The teacher mainly inspire, guide, answer students on their studies and so on. It seems difficult to intervene for University Library. And the needs of library showed differences for different subject MOOCs teaching teams.There are little dependence on library for higher specialized subjects. If the librarians really want to involved in the MOOCs teaching team, they need service innovation. 


\section{B. The morphology changes of teaching reference resources}

Most MOOCs courses usually centre on a theme, no fixed materials, but require a large amount of reference materials. It is a challenge to the current mainstream electronic teaching reference books. The current teaching materials of electronic library mainly include electronic version of paper books and e-books. These electronic reference materials scatter in various library databases, and most ones don't blend into course management system, neither associate with the MOOCs platform. Teaching based on MOOCs is carried out by these means: problem oriented, independent, exploration, discussion, digitization of teaching reference resources. It recommends corresponding electronic reference materials according to the teaching content and integrate into the same platform to achieve all seamlessly embedded link with MOOCs.

\section{The copyright problem of electronic resources}

The ideal state of MOOCs is all related electronic resources of the courses will open up to global students, no school or national boundaries. But this kind of teaching form brings the copyright restriction which is more stringent than the traditional classroom teaching. American copyright law sets exemption and flexible terms of the principle in the faceto-face teaching. The copyrighted works can be used without license and pay in it, but the network teaching is not applicable to this kind of clause. If third-party resources are used in the teaching, it has to obtain authorization or permission. Some "Attribution - noncommercial use" license agreement resources which support knowledge sharing shall only apply to non-profit organizations, and cannot be used in MOOCs whose purpose is for the profit. At the same time, facing the global millions of registered students, third-party copyright owners may not be willing to achieve the use license with teachers. In the information resources which student can use, there must have some differences among oncampus and off-campus students. Participation of the library will provide series reference resources which include the open and accessed web resources and a majority of university digital resources from ordering for teachers. The ordering of the resources will be due to copyright agreements and the scope of the license restrictions, and the most students cannot access to them, thus forming the information resources become the barriers to be used . Librarians should assume the responsibility of copyright advisory guidance.

\section{INNOVATION OF SERVICE MODE OF UNIVERSITY LIBRARY BASED ON MOOCS}

MOOCs brings new challenges and opportunities to the University Library. How to carry out the service work is a question that university library should face and think about. The library must be innovative on how to display the information and service. The next service innovations will follow the MOOCs courses, copyright consulting service, learning space service, electronic resources service etc.

\section{A. To set up the information literacy (MOOCs) course}

Literature [2] points out that the most direct way for librarian to involve MOOCs is setting up their own MOOCs course. And the "information literacy" course is the first choice of the library.

The essence of "information literacy" is a basic ability that people need to have in global informationization. In 1989 American Library Association (ALA) proposes the information literacy includes: determine what information when needed, know how to get information, how to appraise and effectively use the required information. The cultivation of information literacy of students always has been a very important content of university library service. Librarians can set up their own( information literacy )MOOCs by their advantages.

Librarians can communicate in the global, impart information literacy skills through the course of information literacy MOOCs, also can know more about MOOCs teaching process, and provide service for other MOOCs courses throughout the whole teaching link.

The university libraries should cooperate with some related departments such as Computer College by taking MOOCs as the platform and jointly set up the information literacy courses. At present, in Guokr.com , Zhongshan University teacher Zhang Zhian sets up a course of "network literacy" [6], Luo Zhaofeng of the University of Science and Technology of China sets up a course of "document management and information analysis" [7], the Wuhan University teacher Huang Ruhua also sets up the "information retrieval" MOOCs course [8]. All of them become the forerunners to carry out the information literacy education of the library through the MOOCs.

\section{B. Provide MOOCs learning space service}

In MOOCs mode, the classroom is in the "cloud", the school is in the "cloud", the learning process can be carried out in any place. The teacher mainly plays a guidance role, learner mainly obtains knowledge by reflection and discussion, taking cooperative learning activities. In this environment, the library can also provide space for teachers and students to do MOOCs activities. In recent years the library built more and more various environment friendly, advanced facilities sharing space, become activity place for MOOCs teacher and learner, provide space and the corresponding supporting services for MOOCs teachers and students to reading, self-study, the party, discussion even test etc. Some of the subject librarians join the MOOCs student forum to help the students to answer the questions. All of these, can improve the utilization rate of library space, enhance the value in use and promote the visualization of library . The New York Public Library (NYPL) tries the mixed learning services and combines with MOOC technology to provide face-to-face help . The library offers space "Learning Center" for the Coursera class. In New York people who register a 6 week course can meet to discuss in the NYPL branch every week, and can get the guidance of assistants[10].The supposition of this experiment is that by reason of lacking teaching support and community, 
it leads to the high rate of stopping studying MOOCs. With the help of the NYPL's Coursera project which provides instructors and social experience to the participants ,prompting them to stay in the learning track.

\section{To provide copyright guidance for the MOOCs}

The copyright problem must be payed attention to avoid in MOOCs. The university library and subject librarians also should be responsible for the consultation of copyright issues and the service of examine and verify which also is the scale that subject librarians serve in. Many of the MOOCs platforms (like Coursera) definitely claim the copyright of all the content must be clear to avoid legal disputes. Duke University provide copyright and licensing service on Coursera Platform for the MOOCs courses to handle the licensing requirements, provide reasonable useful consultation, provide the open resources which can replace the third-party copyright resources, ensure that teachers can make full use of teaching resources to produce its innovative MOOCs[11]. These services are useful and valuable, which can promote accessing to teaching resources without obstacles.

The main copyright problem of MOOCs is the ownership of course's contexts and the ownership and usage of course's sustaining resources. The former involves MOOCs institutions, teachers and students, and the latter mainly relates to the MOOCs organization, library. University library can play a role of copyright consultant to exert the advantage of resources copyright, to provide copyright protecting suggestions for the related parties of the MOOCs platform. Timely discovery, clean and resolve the copyright risk in MOOCs course, to ensure that the third-party curriculum contents accord with the law norms of copyright. The emergence of MOOCs increases the library resources application amount and service scale, which makes the library to procure resources with the optimal price.

\section{The construction and service of MOOCs teaching reference resources}

Digital resources are an important part of course. Teaching reference information include on-class reference resources and off-class extension reading. It is a kind of important literature resources of University in the process of teaching and is the directest and most important reflection of the library which devotes itself to support teaching. Teaching reference information of the MOOCs teaching environment should base on common aspects of teachers, students, teaching platforms and information resources to establish open digital resource library and navigation system of electronic resources by the branch of subjects.

Subject librarians collect, retrieve, fabricate and integrate a variety formats and types of electronic literature resources, such as books, journal articles, chapters, news comment, audio, video, pictures etc and put them into the digital resource database. It requires to cover teaching process completely including teaching design and preparation before class, classroom teaching, homework or feedback, extra- curricular reading. And it can realize social interaction function based on Web2.0 and share resources to all students. At the same time, libraries push and customize subject around the course, and realize the seamlessly embedded association with the MOOCs platform.

The library can also create curriculum resources guidance around the theme, through the libguides platform. At present, libguides curriculum guidance in foreign countries has been widely used in the classroom or online education, and achieved good responses. Libguides, based on the Lib2.0 concept, will also adapt to the MOOCs environment. In the libguides curriculum guidance, librarians, teachers and students can become partners, provide rich resources for real-time dynamic, and realize the seamlessly embedded association with the MOOCs platform.

\section{CONCLUSIONS}

MOOCs, a new teaching model, has been the rapid development and attracted wide attention in recent years, has a great influence on the higher education and brought great opportunity and challenge to university library. This paper describes the impact of development of MOOCs' on University Libraries, puts forward that university library should participate in the construction of offer MOOCs courses which rich in information literacy, strengthen the construction of reference resources, the guidances of copyrights and the services of learning's space to build MOOCS and provide innovative services for the teachers and students under MOOCs. To make it play a greater and more active role in the environment of MOOCs.

\section{ACKNOWLEDGMENT}

The research work was supported by the Innovation Project of Shandong Graduate Education under Grant No. SDYC14013.

\section{REFERENCES}

[1] Bulter B. Massive Open Online Courses:Legal and policy issues for research libraries [J].Association of Research Libraries Issue Brief,2012(12):1-15.

[2] Mahraj K.Using information expertise to enhance massive open online courses [J].Public Services Quarterly,2012,8(4):359-368.

[3] Tianzhen F.Jiangping Z.Strategies of university libraries responding to the MOOC challenge[J]. Journal of Academic Libraries,2014.1:2024

[4] Wei Z,Xia L. Exploration and thinking on the service of university library under the background of MOOCs[J].Library Theory and Practice,2014.9:59-63

[5] Jianping L, Youqun S, Zaixin R.Research on university library Elearning environment construction under MOOCs trend.Applied Mechanics and Materials,2014(543-547):4298-4303

[6] Zhian Z.Network literacy.[2014-1028]http://mooc.guokr.com/course/1777/ Network literacy/

[7] Zhaofeng L. Document management and information analysis [20149-17].http://mooc.guokr.com/course/1301/Document management and information analysis/

[8] Ruhua H.Information retrieval [2014-9-1] http://mooc.guokr.com/course/1874/ Information retrieval/

[9] Cameron B. MOOCs:The challengs for academic librarians.Austrlian academic \& research libraries,2013,44(3):163-175 
[10] Irene G, Curtis K .Can Libraries Save the MOOC? [2014-1106]. http://campustechnology.com/Articles/2014/11/06/CanLibraries-Save-the-MOOC.aspx?Page=1
[11] Lan Y. The library of Duke University as the MOOC program provides copyright licensing 16].http://mooc.lib.szu.edu.cn/?p=2276. service.[2014-6- 